\title{
COLLECTIVE ACCELERATION OF ELECTRONS AND IONS IN A HIGH CURRENT RELATIVISTIC ELECTRON BEAM
}

FINAL REPORT

ON

CONTRACT DE-AC02-80ERT10569

\section{DISCLAIMER}

This report was prepared as an account of work sponsored by an agency of the United States Government. Neither the United States Government nor any agency thereof, nor any of their employees, makes any warranty, express or implied, or assumes any legal liability or responsibility for the accuracy, completeness, or usefulness of any information, apparatus, product, or process disclosed, or represents that its use would not infringe privately owned rights. Reference herein to any specific commercial product, process, or service by trade name, trademark, manufacturer, or otherwise does not necessarily constitute or imply its endorsement, recommendation, or favoring by the United States Government or any agency thereof. The views and opinions of authors expressed herein do not necessarily state or reflect those of the United States Government or any agency thereof.

Prepared by:

John A. Nation

Laboratory of Plasma Studies \& School of Electrical Engineering Cornell University, Ithaca, NY 14853, USA 


\section{DISCLAIMER}

Portions of this document may be illegible in electronic image products. Images are produced from the best available original document. 



\section{Introduction}

This report describes work carried out on DoE contract number DE-AC02-S0ER10569 during the period December 151979 to May 31 1002. The report provides a brief summary of the program objectives, summarizes the main accomplishments and concludes with listings of $\mathrm{Ph} . \mathrm{D}$ degree students supported, and conference and refereed publications.

\section{Technical Program}

The original purpose of this research was an investigation into the use of slow space charge waves on weakly relativistic electron beams for ion acceleration. The work had three main objectives namely, the development of a suitable ion injector, the growth and study of the propoerties of slow space charge waves on an electron beam, and a combination of the two components parts into a suitable proof of principle demonstration of the wave accelerator.

Our work focussed on the first two of these objectives. The injector study was based on the use of a collective accelerator in which protons were accelerated by the fields at the head of an intense relativistic electron beam. Typical parameters for the study were as follows:

$\begin{array}{ll}\text { Electron beam Energy } & 600 \mathrm{keV} \\ \text { Electron Beam Current } & 50 \mathrm{kA} \\ \text { Pulse Duration } & 100 \mathrm{nsec} .\end{array}$

Peak proton energies of up to 20 times the electron beam energy were achieved. The velocity of a $12 \mathrm{MeV}$ proton is $4.75 \times 10^{7} \mathrm{~m} / \mathrm{s}$ and corresponds to a required phase velocity for the slow space charge wave of about $0.16 c$. The bulk of the protons had a lower energy, however there were sufficient protons available for the proof of principle wave accelerator.

The development of a suitable space charge wave on the beam and the control of the wave phase velocity proved to be a formidable task, with a considerable effort required to maintain a high enough quality beam and an even greater effort to control the wave phase velocity. Wave growth was achieved by propagating an uniform electron beam with a current of about $1 \mathrm{kA}$ at a beam energy of about $300 \mathrm{keV}$ through a disk loaded waveguide. The cool center portion of the beam was utilized for the wavegrowth experiments. A wave frequency of $1 \mathrm{GHz}$ was used for these experiments. Good coherent wave trains were obtained and propagated stably through the system. Wave phase velocities as low as $0.06 \mathrm{C}$ were obtained occasionally and phase velocities of $0.12 \mathrm{c}$ could be achieved reliably. The electric field in the wave was estimated at up to $22 \mathrm{MV} / \mathrm{m}$. 
The observed low phase velocities, which were only obtained for times of order 10 nsec., were considerably slower than expected theoretically. Linear theory indicates that the wave phase velocity only goes to zero when the wave frequency is zero and the ratio of the current to the vacuum limiting current is unity. The observed slowing down was attributed to non-linear propagation and the interpretation confirmed from observations of harmonics of the wave frequency. Experiments were carried out to explore the change in the wave velocity which occurs as the beam to limiting current ratio was decreased. A controlled change in the wave phase velocity is of course required for proton acceleration. Changes in the wave phase velocity were measured and qualitatively followed the expected trends. Discrepancies were attributed to non-linear wave slowing which cannot be readily controlled by changes in the beam or struciure geometry. As a result of this we did not suceed in obtaining the required degree of control of the phase velocity to allow us to fabricate a working accelerator and the project was duly terminated in favor of a program which focussed on the generation of ultra high power microwave signals suitable for use in the next linear collider. This program was a natural outgrowth, albeit at higher frequency of the wave studies carried out in the collective ion accelerator research program.

The development of the next linear collider requires the production of ultra high power microwave sources. The sources must not only be very efficient and inexpensive but also must be phase stable. Peak powers of up to $1 \mathrm{GW}$ are required in $\mathrm{X}$ band in pulses of order 100 nsec. in duration. Previous electron accelerators have been driven by klystrons which produce up to about $60 \mathrm{MW}$ at $S$ band $(2.856 \mathrm{GHz})$ in a three microsecond pulse. During the past six years we have devoted our main effort to addressing these requirements. We elected to develop an $\mathrm{X}$ band traveling wave tube amplifier as a logical extension of our earlier work on the slow space charge wave excitation outlined above. Prior work on high power traveling wave devices had been restricted to the development of Backward Wave Oscillators and no Amplifiers had been built. Our rationale for making the transition to an amplifier was that it was relatively straightforward to visualize the phase control from one amplifier to another for a large array of amplifiers driven by a master oscillator, but it was very difficult to envision a similar system for an array of oscillators. At minimum the oscillator array would take longer to phase lock and the locking would require a much greater fraction of the output power of each device.

Our first amplifier design appeared to work satisfactorily with gains of over $30 \mathrm{~dB}$ and with output powers of about $100 \mathrm{MW}$. A detailed study of its characteristics showed that pulse durations of $100 \mathrm{nsec}$ were ackievable and that the bandwidth of the devices were about 30 to $40 \mathrm{MHz}$. This figure was substantially smaller than expected and our efforts focussed on understanding the bandwidth narrowing over expectations based on known lower power device performance. The phenomenon was traced to finite structure length effects and on deeper study also predicted the development of sidebands in the radiation pattern. These were found experimentally and are the result of preferred wavenumbers for the structures resulting from low $Q$ cavity resonances. The resonances are in turn a consequence of small impedance mismatches at the input and output ends 
of the amplifiers. Interactions and wave growth occur at frequencies corresponding to the preferred wavenumbers. At power levels of over about $70 \mathrm{MW}$ we find that the sidebands develop and increase in importance as the power is increased. At $400 \mathrm{MIV}$ the power in the sidebands was $50 \%$ of the total radiated power.

Attempts to increase the output power above $100 \mathrm{MW}$ lead to oscillation of the amplifier. To overcome this problem we developed a severed two stage amplifier in which the gain could be further increased, reaching ultimately a power output of $400 \mathrm{MW}$ at an efficiency of over $40 \%$. As indicated above our concerns then turned to the problem of eliminating the sidebands. Towards the end of the contract iprogram we produced a solution to the problem which will be tested as part of a new research program started this month. The solution is based on the development of a slow wave structure with a very low group velocity. In such a structure the TWT may perhaps be better though of as a series of weakly coupled cavities. Preferred wavenumbers should be of no importance in these devices as the input is isolated from the output for a time equal to the structure length divided by the group velocity. This time is comparable to the if pulse duration consequently thecavity does not get a chance to establish preferred value of the wavenumber. In addition the wave is highly attenuated in transit through the structure much like the regime found in klystrons where the cavities are isolated from each other by extended cut off sections of guide. For the forward going wave the electron beam couples adjacent cavities so the poor coupling in the absence of the beam is of no importance. Finally we note that we have simulated these new structures using the MAGIC code. Results from the simulations confirm that the new structure will eliminate the sidebands.

Approximately a year before the end of the contract we became aware of work in progress at CERN on the use of ferroelectrics as sources of eiectrons and initiated a low level effort in this area. To date we have used them to achieve currents of up to $70 \mathrm{~A}$ at a current density of $70 \mathrm{~A} / \mathrm{cm}^{2}$ in 300 nsec pulses. Current interests lie in determining whether the ferroelectrics will be low emittance sources and how they will perform in If cavities. Work is continuing on this project.

\section{CONCLUSIONS}

Over the duration of the above contract we have completed a substantial body of research on wave growth on intense electron beams. We have reported this work extensively at both conferences and in Journal articles. A listing of the Journal and conference papers arising from this work is appended to the report together with a list of conference presentations. We complete the report vith a listing of graduate students who completed their Ph.D. studies on the projects described above. 


\section{CONFERENCE AND REFEREED JOURNAL ARTICLES}

[1] "Collective Acceleration of Metallic Ions," Appl. Phys. Lett. 36, S10 (1980) (J.A. Nation, R. Adler).

[2] "The Collective Acceleration of Protons in Relativistic Electron Beam Propagation in Evacuated Drift Tubes," Phys. Fluids 24, 347 (1981) ( R. Adler, J.A. Nation, and V. Serlin).

[3] "Proton Energy Spectrum Diagnostics for a Collective Accelerator," Rev. Sci. Instr. 52, 698 (1981) ( R. Adler, J.A. Nation, and V. Serlin).

[4] "Application of Space Charge Waves on an IREB to Collective Ion Acceleration," IEEE Trans. Nucl. Sci. NS-28, 3352 (1981) ( G. Providakes, and J.A. Nation).

[5] "Proton Collective Accelerator Studies," Proc. 4th International Topical Conference on High Power Electron and Ion Beam Research and Technology (Palaiseau, France, 1981), II, p. 667 (with G. Providakes, J.A. Nation, and V. Serlin).

[6] "Collective Acceleration Processes Using Waves on Electron Beams," ECFA Conference Proceedings (Oxford, 1982) p. 115.(J.A. Nation,)

[7] "A Compact 1 GW Pulsed Power Source," Rev. Sci. Instruments. 54, 1509 (1983). (J.D.Ivers and J.A. Nation)

[8] "High Current Electron Beam Sources," Applied Space Charge Optics, Chap. 3, p. 171.(1983) (J.A. Nation).

[9] "Electron Beam Wave Accelerators," Proc. 5th International Topical Conference on High Power Electron and Ion Beam Research and Technology (San Francisco, CA, 1983) (with A. Anselmo, D. Fenstermacher, S. Greenwald, J. Ivers, G. Kerslick, J.A. Nation, G. Providakes, and C. Seyler).

[10] "Space-Charge Wave Propagation in Inhomogeneous Waveguides," Phys. Fluids 28, 358 (1985) (A. Anselmo, and J.A. Nation).

[11] "Space-Charge Wave Accelerators," Proc. of the CAS-ECFA-INFN Workshop, Frascati 223 (1985) (J.A. Nation).

[12] "Wave Excitation in Waveguides Below Cut-off," IEEE Trans. Nucl. Sci. NS-32, 5, 3494 (1985) (A. Anselmo, and J.A. Nation). 
[13] "Space-Charge Wavegrowth and Propagation on a Relativistic Electron Beam." IEEE Trans. Nucl. Sci. NS-32, 5. 3497 (1985) ( S. Greenwald. J.A. Nation, and G. Kerslick).

[14] "High Gradient Electron Accelerators using Fast Waves on Beams," Proc. of the 6th International Conference on High Power Beams, Kobe, Japan, June 9-12, 1986, pp. 770-773, ( S. Greenwald, and J.A. Nation).

[15] "Pulse Power Application to Accelerators," Proc. 1986 Symposium on Advanced Acceleration Concepts," Madison, WI, Ed. F. Mills, pp. 46-67, ( A. Anselmo, J.A. Nation, and S. Greenwald).

[16] "A Low Energy Repeater for Studies of E-Beam-Wave Interactions," Proc. 1987 IEEE Particle Accelerator Conference, pp. 91-93 (1987). (With J. D. Ivers, A. Anselmo, J.A. Nation, and Y. Z. Zhang).

[17] "The 'Ultralac': A Collective Wave Accelerator for Ultrarelativistic Particles," Proc. 1987 IEEE Particle Accelerator Conference, pp. 145-147 (19S7) ( A. Anselmo, and J.A. Nation).

[18] "Wavegrowth Technique for Collective Wave Accelerators," Proc. 1987 IEEE Particle Accelerator Conference, pp. 157-160 (1987) ( A. Anselmo, and J.A. Nation).

[19] "Application of High Power, Intense Electron Beams to Ultra High Energy Electron Accelerators," Proc. 1987 Workshop on New Developments in Particle Acceleration Techniques, ECFA-CAS/CERN-1N2P3, Orsay, France, June 1987, 1, pp. 23-32, (J.A. Nation )

[20] "Parametric Growth of Space Charge Waves using a Self Biased Electrostatic Wiggler," ( A. Anselmo, and J.A. Nation ), Phys. of Fluids, 31, (7), 2037- 2046, 1988.

[21] "High Power Traveling Wave Tube (TWT) Amplifier," ( D. Shiffler, and J.A. Nation) Proc. Microwave and Particle Beam Sources and Directed Energy Concepts, 1061, 17-23, 1989 .

[22] "New Accelerator Concepts," Proc. 7th International Topical Conference on High Power Beams - Karlsruhe 1988, 1, 175 - 183 (J.A. Nation).

[23] "Application of Relativistic Electron Beams and High Power Microwaves to Particle Acceleration," ( E. Chojnacki, T. J. Davis, J. D. Ivers, G. S. Kerslick, J.A. Nation, and D. Shiffler), Proc. 7th International Topical Conference on High Power Beams Karlsruhe 1988, II, $870-875$. 
[24] "High Power Traveling Wave Tube Amplifier," ( D. Shiffler, J.A. Nation, and C. B. Wharton) Appl. Phys. Letters, 54, (7), 674. 1983.

[25] "A High Power X Band Relativistic Klystron," ( T. J. Davis. J.A. Nation, and E. Chojnacki, Proc.1989 Particle Accelerator Conf. 1,147-149.

[26] "High Power TWT Experiment," ( D. Shiffler, J. D. Ivers, J.A. Nation, and G. S. Kierslick), Proc. 1989 Particle Accelerator Conf. 1,150-153.

[27] "Upper Hybrid Wave Collective Accelerator Studies," ( E. Chojnacki,J.A. Nation, and T. J. Davis,) Proc. 1989 Particle Accelerator Conf. 3.734-736.

[28] "High Power Traveling Wave Amplifier Experiment," ( D. Shiffler, J. D. Ivers, J.A. Nation, and G. Kerslick, ) Proc. 1990 Conf. on Microwave and Particle Beam Sources and Directed Energy Concepts, 1061, 17-23, 1989.

[29] "A High Power Traveling Wave Tube Amplifier" ( D. Shiffler, J.A. Nation, and G. Kierslick), IEEE Trans on Plasma Science, 18, (3), 497, (1990).

[30] "Gain and Efficiency Studies in a High Power Traveling Wave Tube Amplifier" ( D. Shiffler, J Ivers, J.A. Nation, and G. Kerslick) To be published in Proc.1990 Conference on Microwave and Particle Beam Sources and Directed Energy Concepts.

[31] "On the Bandwidth of a Short Traveling Wave Tube Amplifier" ( L. Schachter, J.A. Nation, and G. Kerslick), J. Appl. Phys. 68, (11), 5874-5882, (1990).

[32] "High Gain, High efficiency TWT Amplifiers Proc 1991 Intense Microwave and Particle Beam Conference, (with J.D. Ivers, G. Kerslick, D. Shiffler, and L. Schachter), 1407, 32-43, (1991).

[33] "Efficiency Increase in a Traveling Wave Tube by Tapering the Phase Velocity of the Wave", ( L. Schachter, and J.A. Nation),Proc. 1991 Intense Microwave and Particle Beam Conference, 1407, 44-56, (1991).

[34] "Sideband Development in a High Power Traveling Wave Tube Microwave Amplifier", ( D. Shiffler, J. D. Ivers, J.A. Nation, L. Schachter and G. Kerslick), Appl. Phys. Letts. 58, (9), 899-901 (1991).

[35] "A high power two stage traveling wave tube amplifier", ( D. Shiffler, J. D. Ivers, J.A. Nation, G. S. Kerslick and L. Schacter, J. Appl. Phys 70 (1), 106, (1991)

[36] "Theoretical studies of high power Cerenkov amplifiers", ( L. Schacter, J.A. Nation, and D. Shiffler), J. Appl. Phys 70 (1), 114, (1991) 
[37] "Pulse Power Driven Trarcling Wave Tube Amplifiers". ( G. Kerslick.J.A. Nation. L. Schachter, D. Shiffler), Proc. 1991 Particle Accelerator Conference.

[38] "High Power X Band Coavial Amplifier Experiments". ( T. Davis, and J.A. Nation) Proc. 1991 Particle Accelerator Conference.

[39] "Electron Emission from Ferroelectric Ceramics", (J. D. Ivers, R. Advani, J.A. Nation, and L.Schachter), Proc. 1991 Particle Accelerator Conference.

[40] "Analysis of a traveling wave tube tuned by a cavity", ( L. Schacter, and J.A. Nation ), J. Appl. Phys. 70, 10, 51S6. 1991

[41] "Development of sidebands in ultra high power traveling wave tube amplifiers" ( D. Shiffler, J.A. Nation, G. S. Kerslick and L. Schacter), Invited paper presented at the IEDM meeting, San Francisco, Nov 1990

[42] "High Power traveling wave tube amplifers for RF accelerators", (D. Shiffler, L. Schacter, J.A. Nation, G. S. Fierslick, T. J. Davis, and J. D. Ivers), Proc. $2^{\text {nd }}$ European Particle Accelerator Conference, Nice. France 1, 994, (1990) 


\section{CONFERENCE PRESENTATIONS}

[1] "Proton Acceleration in Relativistic Electron Beams." Bull. Am. Phys Soc. 25. 1008 (1980).

[2] "Observations on the Behavior of a Slow Charge Wave on an IREB," Bull. Am. Phys. Soc. 26, 922 (1981).

[3] "Energetic Ion Production in a Pinched Beam Diode," Bull. Am. Phys.Soc. 26, 945 (1981).

[4] "Development of the Collective Proton Space Charge Accelerator," Bull. Am. Phys. Soc. 26, 1037 (1981).

[5] "Progress Towards the Slow Space Charge Wave Collective Ion Accelerator," IEEE Conf. on Plasma Sci. (1982).

[6] "Recent Experiments on Collective Ion Acceleration Using Space Charge Waves," IEEE Conf. on Plasma Sci. (1983).

[7] "Phase Velocity Measurements of the Slow Space Charge Wave," Bull. Am. Phys. Soc. 28, (1983).

[8] "Field Measurements of Slow Space Charge Waves," Bull. Am. Phys. Soc. 29, 8, 1354 (1984).

[9] "Collective Ion Acceleration Using Space Charge Waves on Annular Electron Beams," Bull. Am. Phys. Soc. 29, 8, 1355 (1984).

[10] "Nonlinear Space Charge Waves on Relativistic Electron Beams Propagating in Axisymmetric Waveguides," Bull. Am. Phys. Soc. 29, 1354, (1984).

[11] "Generation of High Power Microwave Radiation by Propagation of an Electron Beam Through an Electrostatic Rippled Field," Buli. Am. Phys. Soc. 30, 9, 1511 (1985).

[12] "Studies of the Coupling Between a Relativistic Electron Beam and Slow Wave Structures," Bull. Am. Phys. Soc. 30, 9, 1614 (1985) .

[13] "Parametric Excitation of Large Amplitude Waves on a Relativistic Electron Beam for Particle Acceleration," Bull. Am. Phys. Soc. 30, 9, 1617 (1985). (Invited Paper).

[14] "Growth of Fast Space Charge Waves on an Intense Electron Beam Using an Electrostatic Wiggler," Bull. Am. Phys. Soc. 30, 9, 1634 (1985). 
[15] "On the Coupling of Slow Wave Structures to Electron Beam Modes in a Uniform Guide," IEEE International Conference on Plasma Science, June 3-5, 1985. Conference Record Abstracts, p. 88.

[16] "Parametric Excitation of Waves on an Intense Electron Beam," IEEE International Conference on Plasma Science, June 3-5, 1985. Conference Record Abstracts, p. 85.

[17] "Nonlinear Space Charge Wave Coupling to TM Waveguide Modes Via Wiggler," Bull. Am. Phys. Soc. 30, 1544 (1985).

[18] "High Power B.W.O. Experiments," IEEE International Conference on Plasma Science, June 1-3, 1985

[19] "Design of a Low Voltage, Hybrid Wave Generator," Bull. Am. Phys. Soc. 31, 9, 1464 (1986).

[20] "A Collective Wave Accelerator for Electrons," Bull. Am. Phys. Soc. 31, 9, 1629, (1986).

[21] "Applications of High Power Microwave Radiation to the Acceleration of Electrons," Bull. Am. Phys. Soc. 31, 9, 1505 (1986) .

[22] "Application of Pulse Power Generated Microwaves for Electron Acceleration" Bull. Am Phys. Soc. 34, 9, 1991, 1989.

[23] "High Power Microwave Generation and Particle Accelerators", IEEE International Conference on Plasma Science, Buffalo, N.Y.. May 22-24, 1989 (Invited Paper).

[24] "A severed High Power TWT Amplifier", Bull. Am Phys. Soc. 34, 9, 1991, 1989.

[25] "High Power TWT Amplifiers for RF Accelerators", EPAC Meeting Nice France June 1990.

[26] "Characteristics of a High Efficiency, High Power, X Band TWT Amplifier", IEEE International Conference on Plasma Science, Oakland Ca. May 21-23, 1990 (Invited Paper).

[27] "Large Diameter X Band Coaxial Microwave Amplifiers", Bull. Am. Phys. Soc. $35,9,1937,1990$.

[28] "High Power Severed Traveling Wave Tube Experiments",35,9, 1936, 1990. 
[29] "Optimization of dielectrically-loaded waveguides," Bull. Am. Phys. Soc., 36. 9, 2362 (1991).

[30] "Recent experiments with high power TWTS," Bull. Am. Phys. Soc., 36, 9, 2467 (1991).

[31] "Experiments with dielectric slow wave structure high power TWTS," Bull. Am. Phys. Soc., 36, 9, 2467 (1991).

[32] "Theoretical study of the limiting current in a diode with a ferroelectric cathode," Bull. Am. Phys. Soc., 36, 9, 2379 (1991). 


\section{Ph. D. DEGREE'S}

The following students, who have received $\mathrm{Ph} . \mathrm{D}$. degrees since 1080, were supported entirely or in part on the DoE Contract.

Richard J. Adler, 1980, Original Employment at AFWL. Research on Radlac accelerator system, Current employment with own company North Star Research,Albuquerque. Small Business working on modulators and pulse power systems

George F. Providakes, 1985, Mitre Corp, First position Technical Staff developing gyrotrons for satellite communications. Present position Department Head UHF/SHF Satellite Communications

Daniel F. Fenstermacher 1985, First employment Sloan Research Fellow, Center for Science and International Affairs, Harvard University, Current employment: Analyst and AAAS Fellow, International Security and Commerce at Office of Technology Assessment, Washington, D.C.

Shlomo Greenwald, 1987, Cornell University Original employment. Raphael, Research Scientist, Israeli Government, Current employment Cornell University Research Associate, working on if cavities.

Antonio Anselmo 1987, Varian Co Staff Member doing research in Pulse Power Technology.

Donald A. Shiffler, 1991, First Position Duke University doing FEL Research with John Madey, Assistant Prof. UNM in April 1992

Daniel Koury 1992, Numerical Simulation Specialist for Texas Instruments modelling solid state devices.

Two other former staff completed Post Doctoral Research at Cornell under the aegis of the program. They are:

V. Serlin NRL High Power Microwave Program and

E. Choinacki now at Argonne National Lab. working on Wake Field Accelerators. 